\title{
JUVENTUDE E VIDA ASSOCIATIVA NAS PERIFERIAS DE SÃO PAULO
}

\author{
Gilberto Geribola Moreno*
}

\begin{abstract}
Este artigo apresenta uma reflexão sobre a experiência política de jovens militantes das periferias da cidade de São Paulo. O trabalho se inscreve no esforço por compreender a vida associativa como parte de um processo de singularização dos atores políticos. Parte-se da premissa de que esses atores têm a possibilidade de agenciar elementos do passado e do presente na constituição de um repertório político. O artigo está em diálogo com os trabalhos que estudam o militantismo, enfatizando os processos de socialização política, embora esteja operando na chave analítica da subjetivação política. A reflexão aqui apresentada está baseada no material de uma pesquisa etnográfica multissituada, realizada em associações de bairro das periferias da cidade de São Paulo durante três anos. A análise desse material permite afirmar que os jovens militantes selecionam, se apropriam ou rejeitam alguns elementos políticos do passado, difusos sobre o território a partir de sua própria experiência social no universo da política. Sem refutar ou se submeter inteiramente às heranças do passado, os jovens militantes recriam diferentes relações políticas e novas configurações sociais.

Palavras-chave: Juventude. Política. Relações geracionais. Subjetivação. Periferia.
\end{abstract}

\section{INTRODUÇÃO}

Este artigo tem por objetivo apresentar uma reflexão sobre a experiência política de jovens militantes que atuam em associações populares das periferias da cidade de São Paulo. Esses militantes e suas associações foram os objetos de estudo de uma pesquisa etnográfica multissituada (Marcus, 1995), que abordou um conjunto de cinco espaços associativos representativos de diferentes períodos históricos da cidade. ${ }^{1}$ A pesquisa realizada pelo autor visava a compreender as diferentes dimensões da ação coletiva e as percepções sobre as práticas desenvolvidas pelos sujeitos nas periferias da cidade de São Paulo, tendo por problemática as possíveis linhas de continuidade ou ruptura

* Universidade Federal da Integração Latino Americana UNILA.

Av. Silvio Américo Sasdelli, 1842 - Vila A, Edifício Comercial Lorivo. Cep: 85866-000. Caixa Postal 2044. Foz do Iguaçu - Paraná - Brasil. geribolamoreno@mail.com

${ }^{1}$ Trata-se de minha pesquisa de doutorado "Tudo que a gente faz na quebrada é política": vida associativa nas bordas da cidade. Defendida junto ao programa de pós-graduação da Faculdade de Educação da Universidade de São Paulo. A pesquisa contou com apoio financeiro do CNPq. presentes na experiência política das diferentes gerações que atuam nos espaços associativos dos bairros periféricos. Foi abordado, por meio da etnografia, um conjunto de espaços associativos na periferia da zona sul da cidade de São Paulo, composto por: uma associação remanescente das Comunidades Eclesiais de Base; outra originária das lutas por creches e benfeitorias públicas dos anos 1970-80; uma com atuação no campo da cultura; uma vinculada ao futebol de várzea e ao samba; e uma associação ligada a um vereador notabilizado por trocar favores com sua base eleitoral.

Este trabalho discorre, em um primeiro momento e sucintamente, sobre o desenvolvimento da pesquisa de campo para, em seguida, descrever os espaços associativos sobre os quais se apoia este artigo. Em um terceiro momento, apresentam-se algumas percepções apontadas pelos membros desses espaços sobre sua ação e as relações entre as diferentes gerações de militantes no âmbito da vida associativa compreendida por eles como constituinte do universo da política. 


\section{ETNOGRAFIA DA VIDA ASSOCIATIVA}

Ao abordar a vida associativa com foco sobre a problemática da ação coletiva nas periferias da cidade de São Paulo, considerei como campo de pesquisa diferentes espaços associativos $^{2}$ bem como a atuação de alguns participantes nesses espaços como os elementos que possibilitariam uma aproximação empírica da noção sociológica de ação coletiva e observá-la como uma prática desenvolvida pelos atores sociais. Parecia-me ser preciso esse recorte, pois, para perseguir etnograficamente essa categoria, fazia-se necessário delimitar um campo de investigação empírico onde a ação ou um conjunto de ações se realizasse a partir da iniciativa e interação dos atores. Assim, parti da compreensão de que:

Em meu ambiente de pesquisa, a ação coletiva recebe outras denominações, especi$\infty$ ficamente êmicas, que se referem a fenômeసे nos similares. Quando se inquirem os atores هं sociais sobre suas ações nos espaços associaivos, eles afirmam estar "no movimento", "na luta" ou "fazendo política", redefinindo a categoria política como uma ação que se desenvolve no bairro e, portanto, se apresenta para além dos espaços institucionais. Esta afirmação pode ser observada no seguinte trecho de uma entrevista:

A casa não é um lugar só de se reunir, de dar cursos, de atender idosos e tal. É um espaço político porque aqui a gente cria uma resistência. Aqui a gente faz política do dia a dia, junto do povo, por-

Foram abordados cinco espaços associativos. As reflexões apresentadas neste artigo estão apoiadas nos registros das observações de três desses espaços.

\section{. 然}

\section{(a)

\section{os} de sus prátios como acôs políticas, mento de suas práticas como ações políticas, mesmo aquelas voltadas exclusivamente para as atividades circunscritas ao interior das associações.

\begin{abstract}
Não tem essa dos caras virem aqui e quererem faturar em cima do nosso trabalho. Porque quem tá na base somos nós. Nós é que fazemos a política mesmo que importa, que fazemos o movimento que vai transformar a quebrada. Os políticos só querem saber do deles e aparecer na quebrada no tempo das eleições (Marcos, poeta 24 anos, SA).
\end{abstract}

Esses depoimentos apontam duas dimensões da política. Uma compreendida como um conjunto de relações sociais estabelecido

\footnotetext{
${ }^{3}$ Os nomes dos entrevistados e dos espaços associativos foram trocados para lhes garantir o anonimato. Para que o leitor identifique os locais de atuação dos depoentes todos terão sua idade e o local de atuação especificados, após sua identificação nominal. Por questões estilísticas adotarei as iniciais dos espaços associativos, por exemplo: $A M L$ para Associação Mulheres na Luta, $A S$ para Sarau do Alfredo, SSJO para Sociedade São José Operário.
} 
pelas pessoas em interação nos espaços associativos e na sociedade (Arendt, 2001, 2007), e outra como as ações desenvolvidas no âmbito do Estado, de seus aparelhos, da política institucional e de seus diferentes agentes, especialmente marcada pela ação dos políticos e do calendário eleitoral, como observara Palmeira (2001). Nesse ambiente, contudo, parece prevalecer em importância a política que se desenvolve no estabelecimento de laços sociais, a qual redunda na ação coletiva com vistas a algum fim específico, como a reivindicação de um bem de uso coletivo, a busca de melhores condições de vida, as ações comunitárias, as relações de sociabilidade voltadas para o bem comum através ou não do estabelecimento de relações com o aparelho de Estado.

Embora eu reconheça a importância dos trabalhos que abordam a política a partir de uma perspectiva normativa, pretendo apresentar uma abordagem sobre a vida associativa norteada pela antropologia da política (Kuschnir, 2000, 2007) e, nesse sentido, tentar apontar aquilo “que, 'do ponto de vista nativo', é considerado como política” (Goldman, 2006), ou que faz parte do universo da política. Friso que o foco do trabalho recai sobre determinado território das periferias da cidade de São Paulo e sobre as relações intergeracionais no interior dos espaços associativos.

A definição do território e das associações de moradores para a realização da pesquisa na qual se apoia este artigo tomou por base a história dos movimentos populares na cidade de São Paulo. Ao definir os grupos a serem pesquisados, optei por uma região cujo associativismo fosse efervescente, apresentando uma variedade de espaços de participação que comportassem grupos representativos de diferentes formas de organização popular. Ao mesmo tempo, esse território e suas associações deveriam, de alguma maneira, remeter a tipos distintos de práticas políticas que, em alguma medida, fossem representativas de diferentes períodos do associativismo popular. Busquei, enfim, estabelecer um conjunto de associações que me permitissem uma visão das diferentes entidades, algumas remanescentes dos anos 1970-80, passando pelos anos 1990 até os dias atuais.

Ao realizar o recorte territorial para a pesquisa, optei pela periferia da região sul da cidade de São Paulo, trabalhando nos bairros de Capão Redondo, M’boi Mirim e Campo Limpo. Movia-me o interesse pela vida associativa em um ambiente marcado, segundo alguns estudos sociológicos (Feltran, 2008; Telles; Cabanes, 2006), por certa ruptura nas lógicas que compunham os modos de vida das camadas populares e pela centralidade da violência como dispositivo ordenador das relações sociais. Parecia-me que uma etnografia multissituada (Marcus, 1995) permitiria que a pesquisa não ficasse circunscrita apenas a um espaço associativo, possibilitando uma visão sobre um conjunto de relações sociais relacionadas ao universo da vida associativa, o qual, em alguma medida, poderia sinalizar linhas de continuidades e não apenas de rupturas nas práticas políticas e associativas nas periferias.

Os critérios para a seleção das associações seguiram algumas indicações dos moradores, e a representatividade foi auferida por mim a partir de minhas deambulações pelas periferias bem como pelas leituras e indicações que apontavam a importância de determinadas manifestações associativas em certos períodos. As características consideradas relevantes para compor o grupo de associações foram as seguintes: o histórico da associação na região; a constante referência à associação nos depoimentos de alguns moradores; o fato de ser representativa de alguma expressão associativa vinculada a diferentes períodos históricos da cidade; e sua visibilidade como espaço público.

A partir desses critérios, elenquei um conjunto de associações que possibilitassem observar diferenças e cujos perfis remetessem a distintos períodos vivenciados pelos moradores da região: a Sociedade São José Operário: associação ligada à Igreja Católica cuja parte expressiva dos participantes é originária das Comunidades Eclesiais de Base, conhecidas 
como importantes instrumentos de organização popular nos anos 1970; a Associação Mulheres em Luta, originária dos Clubes de Mães e da luta pela legalização de terrenos nas periferias da cidade; a Associação Vila Conceição, ligada ao samba e ao futebol de várzea; o Sarau do Alfredo, encontro de poetas e artistas para expressão de suas produções culturais; a Associação Vila Zita, entidade com marcantes relações com um parlamentar, que se orienta pela prática de troca de favores com sua base eleitoral.

Desse modo, definiu-se um "circuito etnográfico"4 que passei a acompanhar através da participação em diferentes encontros desses espaços associativos. Essa parte do trabalho de campo exigiu que eu estabelecesse uma rotina de pesquisa com vistas a acompanhar algumas atividades e as dinâmicas cotidianas das associações. Aquelas com atividades diárias foram acompanhadas um número maior de vezes, recebendo visitas semanais e respeitando-se certa alternância dos dias. Isso se deu especificamente na Sociedade São José Operário, na Associação Mulheres em Luta e na Associação Vila Conceição. Ao mesmo tempo acompanhei, nessas associações, alguns encontros extraordinários voltados para as comemorações e festas, ou para a tomada de decisões a respeito de algum assunto emergencial, bem como algumas manifestações organizadas pelos grupos, tais como caminhadas, marchas, manifestações por transporte etc. Para o Sarau do Alfredo e a Associação da Vila Zita, o critério foi acompanhar os dias de sarau no primeiro, e as reuniões ordinárias na segunda. Inspirando-me em Whyte (2005), adotei um caderno de campo específico para cada associação, no qual registrei as impressões de minhas visitas. De posse de cinco cadernos com os registros de campo, eu imaginava ser mais fácil acessar os dados de cada grupo. Quando me deparei com o material, estabeleci alguns temas descritores e recorrentes nos diferentes espaços, de modo a visualizar a ocorrência ou a ausência de um

${ }^{4}$ Inspiro-me na noção de circuito desenvolvida em Magnani (2002). ou outro tema nos diferentes espaços associativos. Enquanto realizava a pesquisa de campo, selecionei alguns participantes para entrevista. Esse conjunto de entrevistas semiestruturadas auxiliou na compreensão ou permitiu ampliar a percepção sobre alguns detalhes que haviam passado despercebidos durante as observações etnográficas. Essas entrevistas foram um importante material complementar às observações de campo.

A seguir, no intuito de situar o leitor no ambiente da pesquisa, relato sucintamente minhas observações sobre três associações nas quais se apoia este artigo.

\section{SOCIEDADE SÃO JOSÉ OPERÁ- $\mathrm{RIO}^{5}$}

A opção por trabalhar com um conjunto de espaços associativos exigiu, para cada grupo, diferentes estratégias de aproximação, de entrada em campo, de apresentação do projeto e de estabelecimento de vínculos para a realização da pesquisa. Desse conjunto de entidades, apenas na Sociedade São José Operário eu pude contar com o apoio de uma "informante privilegiada” que acompanha essa associação desde antes de sua fundação formal em 1988. Embora essa associação tenha sido fundada nessa data como pessoa jurídica, ela tem uma ação política na região desde os anos 1970, e parte de seus membros é oriunda daqueles anos. A formalização da associação como uma entidade jurídica se deu com vistas à captação de recursos financeiros públicos e privados

${ }^{5}$ Decidir pelo anonimato das associações e dos militantes foi uma tarefa difícil. No grupo pesquisado, há espaços associativos muito reconhecidos e outros nem tanto. Isso colocou o problema de alguns serem facilmente identificáveis, o que tornaria sem nenhum efeito a tentativa do anonimato. Alguns militantes, ao serem perguntados sobre seu desejo de anonimato, manifestaram sua preferência pelo registro de seus nomes, talvez como uma forma de reconhecimento de sua ação política. Por outro lado, há alguns registros etnográficos que poderiam eventualmente trazer dificuldades para algumas pessoas. Diante desse dilema optei por trocar os nomes de todos os espaços associativos e de pessoas, preservando o anonimato. Acredito que, com isso, cumpro com certo rigor ético perante aqueles que eu acompanhei nesses anos de pesquisa, sem incorrer em prejuízo a meus informantes e à etnografia. 
com o objetivo de desenvolver ações sociais de apoio e assistência à população da região.

Essa associação está sediada próxima a um largo de grande circulação, no qual há uma grande variedade de estabelecimentos comerciais, como pequenos bares, docerias, sorveterias, restaurantes, agências bancárias, pet shoppings, lojas de roupas e calçados. Uma grande loja das Casas Bahia e outra de grandes proporções da concorrente Lojas Marabrás se destacam na paisagem. O largo é cortado por uma via importante, com intenso tráfego de ônibus, caminhões e automóveis. Desde as primeiras horas da manhã até o início da noite, há uma grande movimentação de pessoas no local. No centro do largo, uma base da Polícia Militar construída em alvenaria completa o cenário. A instalação da "base", como é conhecida na região, foi fruto do movimento por segurança encabeçado pela Sociedade São José Operário, nos anos 1990. Pode-se afirmar que o Largo é uma centralidade local para onde confluem o trânsito de automóveis, transporte coletivo e pessoas.

Meu primeiro contato com a Sociedade São José Operário foi em uma sexta-feira de julho de 2011. Era um dia quente e seco do típico inverno paulistano. Acompanhado de minha informante, me encaminhei para uma sala cujo acesso é facultado apenas para aqueles que são expressamente convidados pelo padre ou que são muito familiarizados com a rotina da associação. A sala é composta por várias mesas redondas, com cinco ou seis cadeiras ocupadas por diferentes militantes de variados grupos e movimentos da região. Algumas vezes, ocorrem reuniões concomitantes nessa sala. Uma estante, um aquário e um buffet compõem o mobiliário. Nesse buffet, ficam à disposição café, leite e pães. Nos intervalos das reuniões, esses itens sempre são servidos. Ao fundo, uma porta de vidro separa o interior do exterior, no qual há um pequeno jardim e uma churrasqueira. Nesses espaços, em geral, as conversas são muito descontraídas, sem, no entanto, distanciarem-se completamente dos problemas da região, das dificuldades da luta e do universo da política. Há muita cordialidade entre as pessoas, sempre acompanhada, aqui e ali, de alguma manifestação jocosa.

O grupo de participantes é composto de adultos com idade aparente acima dos quarenta anos e de jovens de diferentes movimentos sociais da região. Alguns participam do grupo de jovens da igreja. Observam-se, recorrentemente, manifestações sobre a "dificuldade de mobilizar as pessoas hoje em dia”, e muitos fazem alusão aos tempos idos, em que "o povo tinha maior interesse na luta" (Marin, 58 anos, SSJO). Outros se mostraram desejosos de "conhecer o que acontece com essa juventude de hoje em dia que não quer saber de nada”. Embora se observe a presença de jovens nas reuniões, é comum ouvir dos adultos que "falta ter participação desses jovens na luta. Pra trazer sangue novo. Isso é o que tá faltando pra gente" (Marta, 48 anos, SSJO).

O padre Alonso, pároco e coordenador de todas as ações da associação, ${ }^{6}$ ao saber da pesquisa a ser desenvolvida, manifestou muito interesse pelo trabalho e, em certo sentido, no mesmo tom que as pessoas haviam adotado anteriormente, enfatizou as dificuldades em mobilizar as pessoas e, em especial, os jovens. "Hoje está mais difícil, mas nós estamos aqui há muitos anos. Por isso, sempre tem uma turma boa com a gente e tem, também, o grupo de jovens que ajuda nas atividades da igreja”. Nesse primeiro encontro, o padre fez algumas indicações de grupos a serem observados e reuniões para serem acompanhadas. Espontaneamente, falou sobre sua atuação política, fazendo uma espécie de apresentação de seu histórico na região. Traçou um rápido painel sobre os políticos que têm base local, manifestando sua simpatia pelo Partido dos Trabalhadores. Ao mesmo tempo, sinalizou quem são seus principais adversários políticos, que "fazem um trabalho sujo na região", particularmente os vereadores Antunes e Marcos

${ }^{6}$ Essa associação desenvolve uma série de atividades junto à população, tais como serviço de creche, acolhimento às mulheres vítimas de violência, alfabetização de adultos, apoio jurídico etc. 
Silva, ${ }^{7}$ ambos políticos do espectro conservador. Esses vereadores são políticos com forte inserção na região, obtendo, nas eleições municipais, uma votação que extrapola a casa da centena de milhares de votos. Antunes não só é campeão de votos para si como foi capaz de transferir seu prestígio eleitoral para os filhos. $O$ vereador elegeu um filho para a assembleia paulista e outro para a câmara federal, com margens estrondosas de votos. Nas últimas eleições, foi reeleito com uma grande votação. É comum que militantes ligados à igreja ou aos movimentos populares afirmem que esse vereador mantém relações com o mundo das ilicitudes e ilegalidades. Contou o padre que, por ocasião de uma batida policial na região, um dos filhos desse vereador foi preso por porte ilegal de arma. Passados alguns dias, o policial que prendeu o filho do vereador foi afastado de suas funções. Segundo o padre, esse é um tipo de ação corriqueira do político, na região. No entanto, diz ele entre risos: "Ele tirou o capitão Nunes, mas não pode transferir o padre de paróquia”. Isso talvez demonstre que a igreja é um espaço no qual a ação coletiva e os militantes não sofrem tão diretamente as injunções dessas lideranças. Ao mesmo tempo, o episódio pode sinalizar certa perenidade das lideranças ligadas à igreja católica e uma possível continuidade de suas práticas políticas.

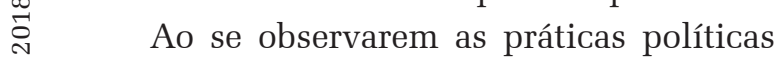
d dessa associação, percebe-se certa ênfase na realização de reuniões entre seus membros, moradores e militantes de movimentos sociais da região e representantes do poder público para discussão e encaminhamentos de solução \& para as mais variadas questões. Em geral, essas : reuniões redundam em alguma forma de apoio i ou auxílio aos moradores, numa ação política ou de formação política dos militantes. Esses encontros seguem um script que implica uma abertura, um desenvolvimento e um fechamento. Todas as reuniões são precedidas de uma pré-

${ }^{7}$ Embora os vereadores sejam atores públicos, eu manterei o anonimato deles, seguindo a orientação geral deste trabalho. -reunião, que se desenvolve na sala cujo acesso é restrito aos mais próximos, ou em encontros formalmente organizados, como, por exemplo, as reuniões da executiva da associação. Essas últimas acontecem toda semana e visam a encaminhar as resoluções das reuniões plenárias ou preparar materiais para serem discutidos nos diferentes grupos que compõem a associação: grupo de educação, de saúde, de violência contra a mulher, etc. As reuniões da executiva têm o caráter de encaminhamento das discussões que se desenvolvem no Fórum em Defesa da Vida, que é um grupo aberto à participação de qualquer pessoa que tenha interesse em acompanhar os trabalhos. Não se trata de um grupo executivo da Sociedade São José Operário. Não há eleições para a constituição da diretoria dessa entidade, mas um grupo de militantes e (ou) funcionários que se articula em torno do padre. Em relação às reuniões dos diferentes núcleos que compõem a associação, sejam elas gerais ou executivas, é permitida a participação de qualquer pessoa. Nas que eu acompanhei, existe também o momento pós-reunião, menos solene, no qual as pessoas conversam temas variados, acertam alguns detalhes que deixaram passar, marcam encontros ou simplesmente "jogam conversa fora". ${ }^{8}$

\section{ASSOCIAÇÃO MULHERES NA LUTA}

Outra entidade que acompanhei em minha pesquisa foi a Associação Mulheres na Luta. Cheguei a ela a partir da busca exploratória que marcou minha opção metodológica no início da pesquisa. Dentre as várias associações que visitei, ela me pareceu importante, por ser constituída por mulheres, algumas das quais tiveram participação nos movimentos sociais dos anos 1970-80, e por apresentar, em seus quadros, um grupo de jovens de ambos os sexos muito atuante nesta associação e na

${ }^{8}$ Comerford (2001) discute as dinâmicas das reuniões nos meios camponeses, apontando os momentos ritualizados da vida política. Em Moreno (2014), discuto esses aspectos nos grupos por mim estudados. 
região. A atuação desses jovens se desenvolve principalmente no campo da cultura, embora não negligenciem a participação nas ações relacionadas às melhorias no bairro e à política de modo geral. Eu não dispunha de uma pessoa que pudesse fazer minha apresentação ao grupo. Em vista disso, iniciei os primeiros contatos por telefone no final de 2011 e marquei uma visita para o dia no qual a diretora estivesse na casa. No primeiro contato presencial, me apresentei como pesquisador para Dona Ana, diretora da Associação, que, por sua vez, me apresentou a outros membros. Explicitei a pesquisa que realizaria na região, seus métodos e os espaços associativos em que eu pretendia trabalhar. Tanto a diretora como outras pessoas demonstraram bastante interesse na pesquisa, tendo em vista "os desafios que a gente tem para atrair a juventude" (Dona Ester, 56 anos, AML). As pessoas mais velhas presentes nesse primeiro encontro manifestaram, de modo geral, a percepção de que "os jovens não estão nem aí pra nada”. Assinalei que havia, naquela associação, um grupo de jovens bastante ativo, porém Dona Ana ponderou: "Sim, temos, mas é pouco. O que a gente vê mesmo é essa molecada por aí. Sem interesse em nada”.

A partir desse primeiro encontro, passei a frequentar esse espaço alguns dias por semana, nos quais era possível observar a rotina local, acompanhar algumas reuniões, presenciar encontros políticos e festas.

Essa associação se formou a partir de um clube de mães e de um grupo de mulheres que participaram dos movimentos sociais por melhorias urbanas nos anos 1970-80, particularmente a luta por creches e pela legalização de terrenos. O grupo foi oficializado como uma associação nos anos 1990. Sua sede está localizada em uma casa alugada em um bairro periférico. Todas as dependências da casa são ocupadas para o exercício de alguma atividade: curso de informática, alfabetização, apoio psicológico, reuniões etc. Na entrada, há uma varanda com materiais diversificados e uma bicicleta de carga repleta de livros para em- préstimo. Essa bicicleta faz parte de um projeto de fomento à leitura desenvolvido pelos jovens que participam da casa e contemplado com apoio financeiro do VAI. ${ }^{9}$ Esse projeto consiste em utilizar a bicicleta para transportar livros pelo bairro e emprestá-los aos moradores. A sala de entrada assemelha-se a uma sala de visitas, com dois grandes sofás e uma estante com muitos livros, fruto de doações para a associação. Uma pequena sala serve de escritório e, ao lado dela. há uma sala de aula na qual ocorrem os cursos de alfabetização de adultos. A Casa tem ainda uma sala de informática com vários computadores, voltada para a oferta de cursos frequentados majoritariamente por jovens. Em frente, há outra sala voltada para o atendimento psicológico à população local. Uma cozinha completa a parte principal do espaço. Nos fundos, há uma sala que é a sede de um banco comunitário, projeto voltado para a concessão de microcrédito aos moradores do bairro. Esse banco foi desenvolvido por iniciativa dos jovens da associação, seguindo os preceitos da economia solidária. Através dessa iniciativa implantou-se uma moeda alternativa no bairro. ${ }^{10}$ Duas salas menores servem como depósito. Há um espaço maior, nos fundos da casa, voltado para a convivência e realização de festas, encontros e reuniões plenárias. Nele, há dois banheiros. Na sala da entrada, alguns pôsteres sinalizam um ambiente alinhado com o campo político das esquerdas como, por exemplo, o indefectível cartaz de Che Guevara com sua boina de lado. No mural do corredor que liga todos os cômodos, a frase escrita à mão - "Mulher bonita é a mulher que luta" completa o cenário. Em diferentes momentos,

${ }^{9}$ Criado em 2003, o programa VAI, Valorização de Iniciativas Culturais, da Secretaria Municipal de Cultura, subsidia iniciativas culturais de jovens, principalmente de baixa renda, com idade entre 18 e 29 anos. Maiores informações: www.prefeitura.sp.gov.br/cidade/secretarias/ cultura/fomentos/index.php?p=7276

${ }^{10}$ Os bancos comunitários são iniciativas desenvolvidas por grupos de moradores e voltadas para o financiamento de atividades econômicas e o desenvolvimento local. Em geral, essas iniciativas implementam uma moeda alternativa àquela de circulação nacional e oficial. Para uma maior aproximação do desenvolvimento dos bancos comunitários, ver: Singer, 2010; Beatriz, 2012 entre outros. 
seus membros enfatizam a importância de se diferenciarem da política normativa, distinguindo-se dos partidos e acentuando a proeminência da luta. "A nossa entidade tem que ser suprapartidária apesar de eu ter minhas convicções. As pessoas não podem identificar aqui com esse ou aquele partido, porque isso desmobiliza a luta” (Dona Ana). No mesmo sentido, Antônio afirma: "Não que os partidos não sejam importantes. Eles são, mas para o trabalho em outra esfera. Aqui, na base, o importante somos nós que também somos da base, que também somos povo". Regularmente, a associação realiza eleições para a composição de sua diretoria, da qual fazem parte velhos e jovens militantes, mulheres e homens.

\section{SARAU DO ALFREDO}

Em vista da importância que as manifestações culturais das periferias ganharam nos últimos anos, defini que seria importante acompanhar um espaço associativo voltado para a promoção e divulgação da produção cultural das periferias. Há uma grande quantidade de manifestações culturais e de grupos de diferentes linguagens mais ou menos formalizados nas periferias da cidade. Esses $\infty$ grupos, em geral, não apresentam o modo de స్ె organização de uma associação, mas, desde 凶ં as primeiras observações de campo, são espaços perceptíveis de sociabilidade juvenil.

${ }^{11}$ A importância desses eventos e grupos culturais pode ser atestada pela crescente exposição pública dos traba-
O Sarau do Alfredo tem frequência semanal, reunindo poetas, músicos, atores, performers, agitadores culturais e militantes políticos no bar de propriedade do Alfredo, na região metropolitana de São Paulo. ${ }^{12} \mathrm{O}$ bar está localizado em uma esquina movimentada nos extremos da cidade. O espaço comporta um salão com algumas mesas e cadeiras e um pequeno balcão de alvenaria ligado a uma cozinha, na qual se preparam pastéis e pequenas porções. Não há cartazes de bebidas alcoólicas nas paredes. Esse fato é retratado com orgulho por Alfredo quando se refere a seu bar, embora se vendam cervejas e bebidas alcoólicas no local. Ao lado do balcão, há uma pequena estante repleta de livros, manuseados livremente pelos frequentadores do sarau.

Esse sarau tem características que o distinguem de outros e, em especial, do mais conhecido, o Sarau da Cooperifa. ${ }^{13}$ Nele, como evidencia Nascimento (2011), há uma organização prévia às apresentações, com através da inscrição para as declamações dos poemas. Observa-se também preferência por "poetas assíduos, [...] a exigência do silêncio dos espectadores enquanto as declamações estiverem sendo realizadas e os aplausos no momento de anúncio do nome de quem irá se apresentar e ao final de cada apresentação." (Nascimento, 2011, p. 23). A partir de minhas observações, eu pude perceber que, no Sarau do Alfredo, ocorre uma maior participação improvisada dos presentes, não se privilegiando a assiduidade, mas o desejo de falar. Fato revelado pela constante interpelação de Alfredo: "Quem quer falar agora, declamar uma poesia?" As manifestações dos presentes podem

lhos dos grupos, que redundaram em encontros como o denominado "Estéticas das Periferias", realizados em 2011, 2012 e 2013. A crescente produção acadêmica sobre o tema e os grupos também evidenciam a magnitude do fenômeno.

12 Parte dessa narrativa será feita no presente, embora o Sarau do Alfredo tenha encerrado suas atividades no local onde permaneceu por oito anos. Atualmente, os encontros acontecem às segundas-feiras, em um espaço dedicado a outras atividades culturais e em eventos itinerantes.

${ }^{13}$ Para uma descrição do Sarau da Cooperifa, ver Nascimento, 2011. 
versar sobre problemas sociais, questões políticas, apresentações de músicos, stand up shows. Há um intenso burburinho de vozes e, quando Alfredo pede que se faça silêncio, as pessoas param de falar por um átimo de segundo e, em seguida, voltam a conversar. Muitas vezes, assisti a manifestações de pessoas ligadas aos movimentos de moradia, dos sem teto, meninos e meninas de rua e muitos discursos anticapitalistas. A Revolução, assim em letras maiúsculas, como uma categoria ontológica está presente em muitas intervenções. Dos saraus que já observei, esse me parece ser o que apresenta o maior número de discursos politizados no sentido de enfatizarem temas como revolução, greves, lutas populares etc. Concomitantemente, o clima de festa e confraternização é uma marca do encontro, com destaque para o estimulo de Alfredo à participação das pessoas e aos improvisos de última hora.

As atividades começam por volta das 21h30min, às segundas feiras. Em geral, quando Alfredo chega ao bar, ele cumprimenta a todos individualmente e pergunta, um a um, se "vai declamar uma poesia”, ou então amplia as possibilidades de intervenção, perguntando: "Você tem alguma coisa para apresentar hoje"? De acordo com as respostas, Alfredo organiza as apresentações sempre contando com um grupo de participantes assíduos do sarau. Após passar por todas as mesas e pelas pessoas que eventualmente estejam em pé ele, distribui alguns livros sobre as mesas. Um ou outro participante toma um livro para si, o folheia e lê. O público é composto, em sua maioria, por jovens, mas há pessoas de idades em torno e acima dos cinquenta anos. Percebe-se que o sarau é um lugar privilegiado de frequência juvenil e de encontros intergeracionais. Entre os jovens, observa-se uma miríade de estilos, passando pelos roqueiros, rastas, rappers e alternativos.

Em geral, Alfredo inicia o sarau pedindo silêncio para ler um trecho de livro e comentá-lo. - Vamos tentar fazer um sarau silencioso? Vamos tentar?
É comum que ele não obtenha respaldo em seu pedido e siga com a leitura do trecho escolhido do livro realizando pequenas pausas para tecer algum comentário. Essas leituras não se limitam à literatura produzida por autores das periferias, mas abrange autores canônicos, dicas de saúde, temas políticos e históricos. Em seguida, convoca as pessoas para declamarem seus poemas ou para a realização de performances no palco, um pequeno espaço construído em alvenaria, trinta centímetros acima do chão.

Algumas vezes, Alfredo reveza com outros participantes o papel de mestre de cerimônias do encontro, por exemplo, com Marcos, jovem poeta e militante cultural ${ }^{14}$, frequentador assíduo do sarau e participante da Associação Mulheres em Luta. Aliás, todos os jovens que atuam nessa associação participam com muita frequência dos saraus da região. Para esses jovens, os saraus e, em particular, o Sarau do Alfredo, são mais do que lugares para declamar e divulgar sua produção poética e artística. Nas palavras de Mauro (24 anos/SA), “... o sarau não é só um espaço de declamar poesia. É um espaço também de articulação, de trocar ideias. Por isso, aquele buchicho de todo mundo conversando. Eu mesmo já assinei contrato pra apresentar nosso trabalho em cima do balcão do Alfredo". Ou, como se expressa Antônio (26, AML), quase em uníssono ao explicar para uma visitante as distinções entre este e outros saraus: "O Sarau do Alfredo não é um lugar só de declamar poesia, como outros saraus que têm por aí. É um lugar também de se criar, de se pensar e discutir propostas de lutas para a quebrada".

Segundo Marcos (24 anos, SA, AML), poeta e ativista cultural da região:

Não adianta ficar nesse negócio de só declamar poesia, de vir aí e falar uma pá de coisas e não fazer nada. Ou pior, fazer só pra si, como a gente vê uns caras ai que falam em nome da quebrada, mas só

${ }^{14}$ Ao caracterizar esses dois atores, eu introduzo o termo militante em função de os mesmos terem se autoidentificado como militantes culturais. 
veem o lado deles. Aqui é da hora por isso. Aqui a gente articula uma pá de questões, tá ligado? É isso, aqui é um lugar de articulação das ideias pra luta.

Embora apresente essa dimensão marcada pela perspectiva da ação política, os dados de caderno de campo demonstram que esse sarau é também um espaço de fruição e lazer, principalmente para muitos dos jovens frequentadores, que vão ali para se divertir ou se expressar sem maiores compromissos com a ação política. "Eu adoro vir aqui. Venho toda segunda. Quando tá acabando o horário de trabalho, eu já fico imaginando encontrar o pessoal. Ouvir as poesias. Eu não escrevo, mas gosto muito de ver o pessoal declamando." (Viviane, 28, frequentadora do sarau). Enfim, pode-se afirmar que o sarau é um espaço polissêmico, no qual habitam diferentes grupos juvenis, manifestações e desejos. Ele é um ambiente de sociabilidade juvenil, encontro de poetas e artistas, espaço de ações políticas e de articulação de ações no bairro.

\section{POLÍTICA E SUBJETIVAÇÃO}

Rancière (1998) afirma que a política apresenta efeitos de subjetivação no sentido de uma singularização do sujeito, não como $\infty$ uma individualidade à parte, mas sim como ลิ um processo que opera em relação a outro. PerФั gunta o autor: "O que é um processo de subjeळं tivação? É a formação de um que não é um $e u$, \& mas a relação de um eu a um outro" (Rancière, 1998, p. 118). Portanto, os processos de subjetivação são da ordem da esfera das relações \& sociais e do espaço público. Não se trata de ¿ um processo relacionado à dimensão privada da vida, mas de um conjunto de relações nas quais os indivíduos se constituem em sujeitos. Segundo Deleuze (1992),

... os processos de subjetivação nada têm a ver com a “a vida privada”, mas designam a operação pela qual indivíduos ou comunidades se constituem como sujeitos, à margem dos saberes constituídos e dos poderes estabelecidos, podendo dar lugar a novos saberes e poderes (Deleuze, 1992, p. 217)

Aproximando-se dessa percepção, porém partindo de outra perspectiva teórica, Touraine (1999) afirma que a dimensão coletiva e a dimensão individual se integram, constituindo uma mesma configuração que, incidindo sobre as individualidades, constroem os atores coletivos e, concomitantemente, os sujeitos da ação coletiva. Portanto, observa-se, nas diferentes perspectivas teóricas, que a vida associativa e os espaços de desenvolvimento da ação coletiva promovem certas subjetividades, ao mesmo tempo em que elas possibilitam a implementação da ação coletiva. Dois movimentos que se retroalimentam constituindo determinadas configurações políticas.

Baseado nessas premissas, compreendo que a atuação dos membros dos espaços associativos comporta elementos de agenciamento que estão além dos aspectos abarcados pela categoria de socialização política, recorrente nos estudos que abordam o militantismo e a participação política com foco sobre as relações entre os grupos geracionais. ${ }^{15}$ Embora sejam pesquisas importantes para a discussão das práticas políticas dos grupos juvenis, a ênfase na transmissão de disposições políticas não permite captar os processos de agenciamento dos indivíduos pertencentes aos segmentos juvenis naquelas atividades que eles interpretam como políticas.

Em meu ambiente de pesquisa, observa-se que, por vezes, são os representantes das novas gerações que acionam componentes das lutas políticas do passado. Especificamente, são acionados aqueles componentes relativos à memória das velhas gerações sobre a ação coletiva e aos saberes acumulados nos anos de disputas políticas no território, com vistas a configurar uma dimensão simbólica, o que lhes confere uma noção de pertencimento à história local e à região.

${ }^{15}$ Refiro-me, particularmente, aos trabalhos de Tomizaki (2007) e Wilson (2010), entre outros. 
Antes de eu conhecer o pessoal da casa eu era bem bobinha. Não tinha muita noção das coisas. Quando eu comecei participar, muita coisa mudou. Eu descobri muita coisa. Tipo que a vila não é só isso que a gente ouve falar. Ouve e vê, né? Tipo tráfico essas coisas. Tem muita história que a gente vai aprendendo nas reuniões, nas discussões e a gente vai tirando umas conclusões, né? Vendo que o lugar que a gente mora também tem seu valor (Mariana, 23 anos, AML).

O acionamento de componentes das lutas do passado se evidencia também na manifestação de Paulo (29 anos), jovem militante dos movimentos sociais da zona sul da cidade de São Paulo, em relação à memória de sua tia, pertencente à geração de militantes dos anos 1970-80. Paulo atua nos movimentos por transporte e de moradia da região. Frequenta também diferentes saraus das periferias, ${ }^{16}$ sendo o mestre de cerimônias do Sarau da Vila Conceição. ${ }^{17} \mathrm{Em}$ um dos saraus, sua tia, que mudara para o Ceará e, pela primeira vez, visitava a família depois de anos, pediu a palavra e fez um pronunciamento sobre a importância das lutas das mulheres na região. Enquanto sua tia falava, Paulo me dizia, apontando para ela: "Viu porque eu sou assim? É por causa disso. Porque vem de uma história que é maior do que a gente que tá aqui, agora. Mesmo que eu não a veja, mesmo que eu não tenha participado disso tudo, quando eu vejo alguém falar da luta eu sei que tem a ver comigo".

Embora possa parecer, à primeira vista, que a experiência social da tia seja o elemento que aciona o ímpeto militante de Paulo, pode-se perceber que é ele que se apropria do depoimento da tia e o instaura como pertencente a uma linha de continuidade com a história de lutas do bairro, relacionando-o à sua própria história. A experiência de participação nas lutas populares narrada pela tia entra na

${ }^{16}$ Nos últimos anos, vem ocorrendo uma profusão de saraus nas periferias paulistanas. Para uma aproximação com o tema, ver Bin (2009) e Nascimento (2011), entre outros.

${ }^{17}$ O Sarau da Vila Conceição foi organizado por Paulo e um grupo de jovens que buscaram atuar no interior da Associação Vila Conceição, um dos espaços associativos nos quais fiz pesquisa etnográfica entre os anos 2009 e 2013. composição do conjunto de elementos que o próprio sujeito julga ser sua herança política. Ao se apropriar de alguns elementos da história de lutas do bairro, Paulo constrói e intenta legitimar sua ação política e cultural na região sem que, para isso, tenha havido um processo formal ou intencional de educação política. É a partir da valorização daquilo que lhe é politicamente relevante que ele constrói, por assim dizer, um discurso da herança para a qual não se evidencia um papel decisivo e proeminente para a tia distante.

No mesmo sentido, Felipe (24 anos, SSJO) afirma, em relação à Sociedade São José Operário, associação na qual escolheu militar: "Eu decidi militar aqui porque aqui é o lugar que eu vejo mais história de luta. Foi por isso que eu escolhi aqui e não outro lugar. Tem muitos espaços por aí, mas é aqui que eu acho mais interessante para eu militar". Nessa manifestação, pode-se perceber a presença dos mesmos elementos: a história, na qual o jovem busca as referências políticas, e o elemento de decisão de militar nessa associação e não em outra, cuja centralidade é o sujeito da ação. O papel da escolha pessoal é central na justificativa para a militância na associação.

Felipe (24 anos), no entanto, compreende que há outros elementos a serem observados:

Eu não posso chegar aqui dizendo o que tem que ser feito. Eu tenho minha ideologia, mas eles já estão fazendo as coisas há muito tempo. Mesmo tendo minhas ideias, eu acho que posso aprender muito com eles, apesar de, às vezes, eu perceber umas coisas que eu acho muito anacrônicas na forma deles levarem a luta. Com o tempo, eu vou colocando o que eu penso de maneira mais clara.

Felipe expressa que tem uma ideologia que antecede sua opção pela associação. Inclusive vê nela algumas características "anacrônicas na forma deles levarem a luta”. Através de um cálculo político, ele espera o momento oportuno para agir na associação em que escolheu militar.

Não se evidenciam, nessas manifesta- 
ções juvenis, elementos que confirmem a existência de um processo intencional de transmissão geracional ou de socialização política das velhas gerações sobre as jovens. Pode-se dizer que, em algum momento da vida desses jovens, eles se transformam em militantes, estabelecendo diferentes relações dos elementos da tradição com aqueles que serão fruto de suas ações coletivas. ${ }^{18} \mathrm{Em}$ outros termos pode-se afirmar que baseados em determinada experiência social esses jovens acionam mecanismos dispersos no tecido social que os levam à ação política.

Meu irmão foi assassinado aqui no bairro por uma besteira. Aí eu mudei do bairro. Mudei para não morrer também. Mas isso foi me incomodando e uns anos depois eu voltei. Quando eu voltei pra cá, eu já tinha ganhado uma experiência de militância com a minha ex-mulher. Eu acho que foi isso. Foi essa história que eu tive e a vontade de contribuir com a quebrada. Pra melhorar a quebrada e não ver mais acontecer com outros moleques o que aconteceu com meu irmão e quase aconteceu comigo (Paulo, 29 anos militante do movimento por moradia e ativista cultural).

De outro lado, há manifestações que pontuam o papel das velhas gerações na constituição de uma "perspectiva militante" de atuação política. O que equivale dizer que, mesmo se centrando em suas escolhas, os jovens militantes buscam referências na experiência

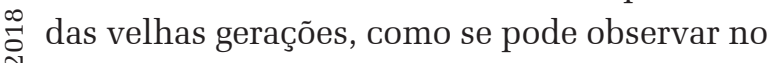
N seguinte depoimento: "A gente pode aprender em qualquer lugar. Eu aprendo todo dia com a Dona Benedita, com a Dona Maria. Porque a gente aprende coisas na luta e coisas que são da luta. A gente aprende e ensina também, $\therefore$ porque é isso que vai ajudar a gente a se liberक tar" (Marcelo, 25 anos, SSJO). bém, as gerações mais velhas como constituintes do momento presente de lutas populares por aparecerem, a seus olhos, como um grupo que guarda a memória das lutas que se desenvolveram na região.

${ }^{18}$ Pudal (in Tomizaki, 2009) demonstra que, para muitos, a militância representa um novo nascimento.
A gente quer os idosos pra somar com a gente na luta. Não é só pra esse negócio de ficar na associação fazendo tricô, esses encontros e tal. É claro que isso é importante pra elas, mas é importante também a gente ter elas na luta, porque elas impõem respeito. Têm umas aí que participaram de tudo que é movimento na quebrada, elas sabem de tudo que aconteceu.

No depoimento desses rapazes, pode-se perceber o acionamento do termo luta como um elemento de ligação entre as gerações, pois é na luta que os encontros geracionais têm seu lugar. Se, nas associações, eles aprendem coisas para a luta, eles também ensinam a outras pessoas, porque é nessa relação entre as velhas e novas gerações que "a gente vai se libertar".

Mauro, outro jovem que atua na associação diz:

Muito do que eu aprendi foi na luta. E até mesmo na rua eu aprendi muitas coisas. Claro que teve a escola também, mas é essa escola que a gente sabe qual é. Que é uma escola que não educa a gente praquilo que a gente quer e praquilo que a gente precisa. Mas sempre tem um professor ou outro que vem com umas ideias e que abre a mente da gente. Claro em todo lugar tem isso. Mas foi depois que eu aprendi mesmo. Eu fui gostar de ler foi encontrando meus camaradas. Quando eu conheci o Márcio e comecei a ir ao sarau foi que eu fui me ligando. Eu acho que eu devo muito ao sarau e ao Márcio. Ele, como é mais velho, fez a minha cabeça. Porque ele é um cara que tá ligado em várias coisas que não tinha aqui na quebrada. Eu acho que foi graças a essas ideias que começou a mudar a quebrada. Que o pessoal se ligou que tinha que batalhar pelas coisas da quebrada. Eu mesmo comecei participar de todo esse movimento porque eu encontrei esse pessoal que já tava fazendo as coisas (24 anos, SA).

O depoimento de Mauro aponta claramente para uma relação que poderia ser tipificada como de tipo figurativa (Mead, [1970], 1997), uma vez que a diferença de idades entre ele e Márcio é de apenas alguns anos. Portanto eles não são membros de grupos geracionais distintos. Nesse caso, observa-se que é no interior do mesmo grupo geracional que os dois constituem relações de trocas de experiências sociais, as quais possibilitam a emergência do 
desejo de participação em Mauro, abrindo, para ele, uma percepção de "que tinha que batalhar pelas coisas da quebrada" e criando, com isso, as condições de sua integração aos espaços associativos.

Tomando como referência grupos geracionais distintos, observa-se, contudo, que esse processo de integração à vida associativa se estabelece marcado por certo conflito, em vista das diferentes perspectivas imputadas à prática política exercida no local, perceptíveis nos questionamentos ou na recusa em aceitar determinadas formas de ação coletiva exercidas por um ou outro grupo geracional. É recorrente, por exemplo, a queixa por parte das velhas gerações sobre a dificuldade de "mobilizar essa juventude que não quer mais saber da luta, só quer saber de ficar na internet, ou, pior, esses que só querem saber de funk" (Dona Ana, 72 anos, AML). Tal queixa corrobora a percepção de senso comum quanto ao desinteresse dos jovens pelo universo da política, ainda que eles participem da vida associativa do bairro.

As declarações das velhas gerações permitem inferir que haveria, em suas observações, provavelmente um desejo de instituir, para as novas gerações de militantes, um sentido de luta orientado pelo histórico da região e por sua percepção geracional da luta política, que seria referenciada naquelas ações consideradas pelas velhas gerações as "lutas mais importantes, lutar por creche para nossas crianças, emprego, moradia. Isso é importante porque é a base da vida: morar e ter o ganha pão" (Dona Marta, 55 anos, SSJO). Ao mesmo tempo, observa-se a constante preocupação das velhas gerações com a manutenção da memória dos grupos e das associações, consubstanciada nos pronunciamentos a respeito do passado de lutas, sendo recorrentes as alusões ao período ditatorial e ao envolvimento da associação nos clubes de mães, movimentos de mulheres por creche e no movimento contra o custo de vida.

Dona Ana (72 anos), presidente da Associação Mulheres na Luta, comenta que:
... esse pessoal mais novo precisa se inteirar mais das coisas. Eles precisam saber da história de luta do povo daqui e de outros lugares, porque hoje eles são todos meio avoados só nesse negócio de Facebook, essas coisas de internet. E por isso que a gente sempre lembra, a gente sempre fala da nossa luta. Da nossa história, que é para eles saberem o quanto já se lutou e ainda tem que se lutar para conseguir as coisas.

Por outro lado, observa-se que, assim como Felipe (24 anos, SSJO) percebe certo anacronismo nas práticas da Associação São José Operário - que o leva a uma participação moderada nessa entidade -, outros jovens modulam sua atuação nesses espaços por meio de um exercício pendular, referenciando-se na história de lutas da associação na região, mas também em sua própria experiência de jovem militante. Antônio (26 anos, AML) declara:

\begin{abstract}
... a gente não quer fazer a política do jeito que elas pensam. Hoje tem uma pá de coisas que são da própria evolução da quebrada de todo esse movimento que vem desde quando a Dona Marisa, a Dona Ester, todas elas militavam. A gente respeita, a gente aprende uma pá de coisas com elas, mas a gente tem que ver também qual é que é daqui pra frente, tá ligado?
\end{abstract}

Em uma das reuniões organizadas pela diretoria da Associação Mulheres na Luta, cujo objetivo era conquistar apoios para uma candidata a vereadora - pertencente ao grupo geracional das velhas militantes - nas eleições municipais de 2012, um jovem disse o seguinte à postulante ao cargo político: "Eu não posso lhe apoiar porque nada me garante que quando você for eleita você não vai fazer aliança com um Maluf da vida ou até coisa pior. A minha contribuição política é aqui na associação, é aqui na luta. É esse meu compromisso e onde eu quero me comprometer" (Júlio/ 25 anos). Evidentemente a candidata ficou em uma saia justíssima, pois nada disso constava do script montado para sua passagem pela associação. Ela ainda tentou argumentar sobre a importância da participação política, mas falava em um registro diferente daquele dos jovens militantes da associação, para os quais a "política desses 
caras está marcada pelos acordos, conchavos e traições ao eleitor" (Marcos, 24 anos). Essa surpreendente denegação da política aponta não um alheamento do universo político, mas uma posição, também política frente às esferas institucionais e normativas da política (Beck, 1999), enfatizando, mais uma vez, a importância da ação no bairro.

No âmbito da política local, as relações entre as gerações, no campo da ação política, são, muitas vezes, referenciadas e legitimadas através da apropriação do histórico de lutas das velhas gerações, como, por exemplo, quando Antônio diz: "a gente aprende uma pá de coisas com elas", referindo-se a Dona Ester e Dona Ana, participantes dos movimentos sociais por melhorias no bairro. Essas relações não excluem automaticamente a disputa e o conflito por posições, recursos e prestígio. Por outro lado, em relação às velhas gerações com vínculos na política normativa-institucional, em alguns momentos se ensaia uma posição de ruptura, mesmo quando o político está no mesmo campo ideológico, como se pode observar no excerto do diálogo relatado acima. Cabe observar que essa ruptura não se efetiva, pois, as observações de campo permitiram perceber que os grupos geracionais operam no interior dos espaços associativos por uma lógica que $\infty$ congrega os movimentos de diferenciação e in¿ें tegração (Bhabha, 2005). Nesse caso especifico, Фं observou-se o esforço do grupo para garantir sua coesão apesar do desconforto das senhoras bilizam outras formas de percepção e de atuação políticas. ouvir isso comigo atuando aqui na igreja. Mas é como eu lhe disse: aqui tem uma história de lutas
Eu sou anarquista. Deve ser até estranho pra você que eu acho importante. Sendo anarquista eu tenho mais liberdade pra atuar porque eu não estou preso a partidos. Então eu tô aqui, mas também tô no Movimento Passe Livre, nas ocupações do centro (Felipe, 24 anos, SSJO).

Esses jovens militantes se distinguem por sua ampliada rede de relações políticas e sociais e pelo consumo da cidade. Tais características os diferenciam sobremaneira dos militantes das velhas gerações, que eram mais afeitos a uma vida centrada no bairro, componente fundamental para a emergência dos movimentos por melhorias urbanas dos anos 1970-80 (Gohn, 1985; Moisés, 1978). Os jovens têm uma percepção que os aproxima das velhas gerações devido à noção de pertencimento ao local e sua valorização; por outro lado se diferenciam ao se articular com outras esferas e dimensões da cidade, seja no universo político, seja naqueles relacionados ao lazer e à fruição. "Quando eu era pequeno, tudo era na quebrada. Meus pais só saíam daqui para trabalhar. Final de semana era na quebrada. Hoje, não. Hoje a gente sai pra vários rolês: Centro Cultural, SESC, Augusta..." (Antônio, 26 anos). A possibilidade e a experiência de transitar por diferentes espaços, alguns ligados ao terceiro setor, outros à cultura e ao lazer, abrem um campo de possibilidades de significação da vida na cidade e contribuem para a proposição de novas formas de ação coletiva. Do mesmo modo, a ampliação dos espaços de sociabilidade propiciada pela circulação pela cidade promove toda uma inventividade política, observável nos diferentes tipos de ação desses jovens.

Essa capacidade de criação de práticas políticas pode ser percebida na organização de um banco comunitário na Associação Mulheres na Luta e na produção e no fomento de atividades culturais, mas, também, na participação desses jovens nos movimentos sociais que adentraram a cena política recente, como o Movimento Passe Livre, a campanha contra a realização da Copa do Mundo no Brasil e o Movimento dos Trabalhadores Sem Teto - 
MTST. Desse modo, a atuação desses jovens nos espaços associativos do bairro é favorecida pela circulação por diferentes espaços que extrapolam esses limites, o que os leva a exercer sua ação política na cidade sem, no entanto, deixar de apontar a importância da luta local como eixo que orienta suas práticas.

Em uma reunião na Sociedade São José Operário, uma jovem militante ligada aos coletivos culturais e grupos feministas e que havia participado das manifestações de junho de 2013 se contrapôs ao bordão "o gigante acordou”, veiculado por alguns grupos e, em especial, pela imprensa por ocasião dessas manifestações, afirmando: "Se o gigante acordou ${ }^{19}$ como estão dizendo, nós, da quebrada, nunca dormimos. A gente tá lutando desde sempre. Se vocês prestarem atenção, vão ver que aqui na quebrada a gente faz política a toda hora" (Vanessa, 23 anos, SSJO). Com sentido próximo a esse, Bruno, um jovem militante ligado aos movimentos por moradia, quando foi entrevistado, afirmou "A gente tá bombando nas quebradas porque a gente vai pra todo lado, pra todas as quebradas", sinalizando uma experiência política que se espraia pelo território da cidade, especialmente por suas periferias, compreendidas e significadas pelos jovens militantes por quebrada. Tal termo denota uma compreensão especifica do espaço periférico, marcado pela percepção de pertencimento, mas não circunscrito à localidade.

Nossa militância é em toda hora e em todo lugar. Nas várias quebradas. Ontem mesmo eu fui pra Guaianases, amanhã a gente tem uma ação no Pinheirinho. Vamos fazer um sarau na Favela do Sapo pra levantar fundos pro pessoal que ficou desalojado com as chuvas e assim vai... (Paulo, 26 anos, AML).

A política, segundo as acepções das camadas populares e dos jovens em particular, pode ser compreendida como uma atividade que transborda tempos e espaços. Quando se

${ }^{19}$ Janice se refere ao bordão “O gigante acordou”, entoado pelos manifestantes e veiculado pela grande mídia durante a cobertura das manifestações. observa a vida associativa e as práticas políticas desenvolvidas pelas novas gerações de militantes das periferias, percebe-se que a ação impetrada no território apresenta características nômades, práticas que se espraiam como rizomas, marcados pela fluidez e imprevisibilidade. "A gente tá na luta. Se não der pra gente fazer a nossa luta em uma associação, a gente faz em outra. Os manos da Conceição ${ }^{20}$ cortaram nosso trabalho lá. Não tem problema, a gente vai pra outro lugar. O importante é continuar a luta” (Bruno, entrevistado).

Holston (2013) aponta que as ações desenvolvidas pelos moradores das periferias da cidade de São Paulo nos anos 1970-80 constituíram-se em uma forma insurgente de cidadania, o que levou os moradores das periferias a se sentirem partícipes da construção da cidade. A nova geração de militantes participa de uma ampla rede de relações e não denega a possibilidade de diálogo e negociação com as esferas institucionais, como aponta Antônio em seu depoimento: "É claro que a gente sabe que tem que conversar com o Marcos Silva. Que tem horas que vai ter que negociar com esses caras". No desenvolvimento de sua prática política, em sua constituição como grupo e na manutenção da vida associativa, esses jovens não operam apenas pela lógica de oposição entre o local e o global, ou por meio de processos de integração à esfera da política normativa. Ao contrário, esses grupos e espaços locais, segundo aponta Bhabha (2005), constituem o próprio lugar da enunciação de um personagem e de constituição de um ator político social.

Nós estamos na base. Nós é que fazemos o trabalho de organizar o povo na luta. É claro que quando precisa a gente vai à subprefeitura, na secretaria. Porque, se não fizer isso, o trabalho também não tem sentido. A gente faz a base pra pressionar os caras. Pra eles verem que a quebrada tá organizada (Bruno, entrevistado).

No âmbito das relações intersubjetivas ${ }^{20}$ Trata-se de uma associação na qual ele atuou como agente cultural. Para maiores informações ver Moreno, 2014. 
que passam pela valorização e pertencimento local, pelo encontro com os iguais e, portanto, pela socialidade -, são urdidas as identificações (Hall, 2005, 2006a) políticas, por vezes fluídas, compósitas e ambivalentes, desses grupos juvenis. A vida associativa nas periferias da cidade não se encontra em uma relação diacrônica, com sentido de ruptura com o passado das lutas populares, como se a ação coletiva fosse realizada em ambientes sociais incomunicáveis. Tampouco está apenas em linha de continuidade repondo permanências e formas tradicionais de atuação política. As ações desenvolvidas pelos jovens militantes apontam para uma configuração na qual encontramos os dois movimentos sendo realizados sincronicamente, no tempo presente, por meio da ação coletiva e da promoção de relações de interação entre as diferentes gerações nos espaços associativos.

No conjunto de manifestações observado nas associações, emergem interações que envolvem as diferentes gerações nas práticas políticas e culturais que se processam através de ações de cooperação, solidariedade, conflito e concorrência. ${ }^{21}$ Compreende-se, portanto, que as relações entre as gerações, no interior das associações, não se processam, como pensa o senso comum, apenas como a externalização de um "conflito entre as gerações", mas స్ํ também não se pode afirmar que as relações 凶ં intergeracionais se desenvolvam apenas em uma linha de transmissão das velhas gerações (2) para as novas.

Os militantes pertencentes aos novos grupos geracionais compreendem a importân-

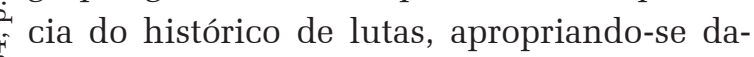
queles elementos que lhes parecem favoráveis ले à ação impetrada atualmente na região.

${ }^{21}$ Attias-Donfut $(1995,1996)$ observou processos de solidariedade intergeracional no interior de grupos familiares. do as mesmas coisas que já foram feitas, porque o bairro mudou muito. E mudou por causa da luta. A gente tem as lutas mais velhas, mas também têm novas lutas e isso se dá na prática da luta política que a gente vem desenvolvendo (Antônio, 26 anos, AML).

Percebe-se, a partir desse depoimento, a articulação dos elementos de uma "tradição" de lutas da região através de uma lógica de acoplamento (Hall, 2006b) desenvolvida na medida das exigências oriundas da ação coletiva impetrada pelas novas gerações. Nessa dimensão da vida associativa, as ações desenvolvidas pelas velhas gerações são apontadas como uma referência política para a constituição, no presente, da ação coletiva dos jovens.

Eu aprendo pra caramba com a Dona Ana, a Dona
Tereza, mesmo com a Júlia que é mais nova do que
elas. Porque elas sabem de um monte de coisas do
Jardim Marajoara. Eu nem tinha nascido e elas já
estavam lutando pelo bairro. Então, é lógico que, co-
nhecendo a luta delas, a gente consegue melhorar a
nossa. Pelo menos não cometer os mesmos erros. Se
é que elas erraram (Márcia, 25 anos, AML).

Pode-se deduzir dessa manifestação que as referências às lutas do passado, no sentido da constituição de uma "tradição" de lutas populares, não estão vinculadas apenas ao passado e a seus agentes, embora o depoimento aponte a importância das velhas gerações como possíveis transmissores de uma memória das práticas políticas. Elas se desenvolvem também pela ação das novas gerações, que mobilizam uma esfera discursiva acerca da ação coletiva, com vistas a legitimar o ator que ingressa no universo associativo no presente. Trata-se, portanto, de uma "tradição" que se atualiza pela ação dos atores. Nas palavras de Bhabha (2005)

O reconhecimento que a tradição outorga é uma forma parcial de identificação. Ao reencenar o passado, este introduz outras temporalidades culturais incomensuráveis na invenção da tradição. Esse processo afasta qualquer acesso imediato a uma identidade original ou a uma tradição 'recebida' (Bhabha, 2005, p. 21). 
Desse modo, pode-se observar que, nas relações políticas das diferentes gerações de militantes, estão em jogo perspectivas e motivações diversas para a mobilização e participação nos espaços associativos. No amplo universo da política, em distintos momentos e temporalidades, essas diferentes gerações se encontram nas tramas nas quais se entrelaçam as dinâmicas políticas, sociais, culturais e os saberes acumulados nas lutas presentes e passadas das camadas populares.

\section{CONSIDERAÇÕES FINAIS}

Este trabalho buscou apreender a presença de certos atores coletivos nas periferias da cidade de São Paulo, tendo por base as noções de ruptura e continuidade nas formas de desenvolvimento da ação coletiva. Ao mesmo tempo, nele se evitou definir a priori um ator coletivo ou sujeito periférico, que estaria ligado às lutas do passado, e, portanto, a uma tradição política. Foram apresentadas as relações entre diferentes grupos geracionais de militantes, apontando as percepções sobre as ações desenvolvidas em distintos tempos e espaços associativos, evidenciando-se a ação dos jovens militantes no acionamento de certos elementos pertencentes às lutas do passado e seu acoplamento às práticas políticas do presente. Assim, observou-se que há manifestações que se coadunam com certa herança das lutas populares dos anos 1970-80, anos de intensa mobilização popular, e outras que apresentam alguns elementos novos ou articulam diferentes aspectos dessa herança a partir da experiência social dos militantes.

Entre as diferentes juventudes que habitam as periferias da cidade de São Paulo, alguns desses atores, em seu conjunto, constituem um importante sujeito político que não deixou de ocupar os espaços associativos, mantendo-se como um expressivo ator coletivo e se constituindo por meio de um conjunto de práticas políticas, redes de interação, trocas sociais e simbólicas que permitem a percepção de uma identificação comum e certa afirmação de pertencimento às periferias e ao universo da política desenvolvida nesse território (Melucci, 2001).

Debatendo os processos de constituição da ação coletiva, Melucci (2001) estabeleceu dois momentos vividos pelos movimentos sociais que se inter-relacionam durante as dinâmicas de desenvolvimento dos atores sociais. Segundo o autor:

Latência e visibilidade são duas condições perma-
nentes dos movimentos e que passam continuamen-
te de uma à outra. Nesta passagem, alguns atores
desaparecem, outros se formam, consolidam-se pro-
cessos de institucionalização e de mobilização, mas
nascem também novos problemas e se revelam no-
vos espaços de conflitos. A forma cultural dos mo-
vimentos abre o problema crucial da relação com
os sistemas políticos, e coloca, em primeiro plano,
o questionamento sobre formas de representação e
de organização adequadas aos novos atores sociais
(2001, p. 123).

Ao acompanhar a vida associativa nas periferias da cidade de São Paulo, foi possível vivenciar, junto a meus interlocutores de trabalho, a condição de visibilidade de alguns grupos e suas práticas políticas. De outro lado, pode-se perceber certa latência de algumas manifestações e grupos de militantes que apontavam novas percepções do campo político.

A emergência de novos atores coletivos, vinculados aos distintos espectros do universo da política, tem lançado desafios à análise social, extrapolando o tempo de realização do trabalho de pesquisa no qual se baseia este artigo. Essas novas configurações do universo da política reclamam novos investimentos analíticos que possam contribuir para os desafios colocados à compreensão da ação coletiva no presente.

Recebido para publicação em 18 de agosto de 2016 Aceito em 02 de agosto de 2018 


\section{REFERÊNCIAS}

ARENDT, H. A condição humana. Rio de Janeiro: Forense Universitária, 2001. 2007.

O que é política? Rio de Janeiro: Bertrand Brasil,

ATTIAS-DONFUT, C. Les double circuit des transmissions. In: __ (Org.)

Les solidarités entre générations. Paris: Nathan, 1995. p. 41-81.

Solidarités et entraides entre générations. In: SINGLY, F. de et al. (Dir.)

La famille en questions: état de la recherche. Paris: Syros, 1996. p. 167-178.

BEATRIZ, M. Z. Economia solidária: caminhos da autonomia coletiva. Curitiba: Juruá, 2012.

BECK, U. Hijos de la liberdad. Buenos Aires: FCE, 1999.

BECKER, H. S. Uma teoría da ação coletiva. Rio de Janeiro: ZAHAR, 1997.

BHABHA, H. K. O local da cultura. Belo Horizonte: Ed; UFMG, 2005.

BIN, M. A. As redes de escritura nas periferias de São Paulo: a palavra como manifestação de cidadania. 2009. 199 p. Tese (Doutorado) - Pontifícia Universidade Católica de São Paulo.

COMERFORD, J. Reuniões Camponesas, sociabilidade e lutas simbólicas. In: PEIRANO, M. (Org.) O dito e o feito: ensaios de antropologia dos rituais. Rio de Janeiro: Relume Dumará, Núcleo de Antropologia da Política/UFRJ, 2001.

DELEUZE, G. Conversações. São Paulo: Editora 34, 1992.

FELTRAN, G. de S. Fronteiras de tensão: um estudo sobre política e violência nas periferias de São Paulo. 2008. 336 p. Campinas. Tese (Doutorado em Ciências Sociais) - UNICAMP

GOHN, M. G. M. A força da periferia: a luta de mulheres por creche em São Paulo. Petrópolis: Vozes, 1985.

GOLDMAN, M. Como funciona a democracia: uma teoria etnográfica da política.

Rio de Janeiro: 7Letras, 2006.

HALL, S. Quem precisa de identidade. In: SILVA, T. T. da.

Identidade e diferença perspectiva dos estudos culturais. ง São Paulo: Vozes, 2005.

A identidade cultural na pós-modernidade. Rio de Janeiro: DP\&A, 2006a

คे . Da diáspora: identidade e mediações culturais. Belo Horizonte: Editora UFMG, 2006b.

¿ HOLSTON, J. Cidadania insurgente: disjunções da $\dot{2}$ democracia e da modernidade no Brasil. São Paulo:

\& Companhia das Letras, 2013.

¿. KUSCHNIR, K. O cotidiano da política. Rio de Janeiro: Jorge Zahar Ed., 2000. 2007

Antropologia da política. Rio de Janeiro: J. Zahar,

MAGNANI, J. G. C. De perto e de dentro: notas para uma etnografia urbana. Revista Brasileira de Ciências Sociais, São Paulo, v. 17, n. 49, 2002. DOI: 10.1590/010269092002000200002

MARCUS, G. Etnography in/of the word system: the emergence of multi sited etnography.Annual Rewiew of anthropology, Palo Alto, California, v. 24, p. 95-117, 1995.

MEAD, M. Cultura y compromisso. Estudio sobre la ruptura generacional. [1970]. Barcelona: Gedisa, 1997.

MELUCCI, A. A Invenção do presente. São Paulo: Editora Vozes, 2001.

MOISÉS, J. A. Classe populares e protesto urbano. 1978. Tese (Doutorado) - FFLCH USP.

MORENO, G. G. Jovens e experiência social na educação de jovens e adultos. 2010. Dissertação (Mestrado em Educação) - Universidade de São Paulo.

"Tudo que a gente faz na quebrada é política" vida associativa nas bordas da cidade. 2014. 230 p. Tese (Doutorado em Educação) - Universidade de São Paulo.

NASCIMENTO, E. P. "E tudo nosso”! Produção cultural na periferia paulistana. 2011. 225 p. Tese (Doutorado em Antropologia Social) - Universidade de São Paulo.

PALMEIRA, M. Política e tempo: nota exploratória. In: PEIRANO, M. (Org.) O dito e o feito: ensaios de antropologia dos rituais. Rio de Janeiro: Relume Dumará, Núcleo de Antropologia da Política/UFRJ, 2001.

PEREIRA, A. B. De rolê pela cidade: os pixadores em São Paulo. 2005. Dissertação (Mestrado em Antropologia Social) - Universidade de São Paulo.

RANCIéRE, J. Aux bords du politique.Paris: Gallimard, 1998.

SINGER, P. I. Introdução à economia solidária. São Paulo: Editora Fundação Perseu Abramo, 2010.

TELLES, V. da S.; CABANES, R. Nas tramas da cidade: trajetórias urbanas e seus territórios. São Paulo: Humanitas, 2006.

TOMIZAKI, K. Ser metalúrgico no $A B C$ : rupturas e continuidades nas relações intergeracionais da classe trabalhadora. Campinas: CMU publicações, 2007.

Da militância ao estudo do militantismo: a trajetória de um politólogo. Entrevista com Bernard Pudal. ProPosições, São Paulo, v.20, n. 2, p. 129-138, 2009.

TOURAINE, A. Podemos viver juntos? São Paulo: Editora Vozes, 1999

WHYTE, W. F. Sociedade de esquina: a estrutura social de uma área urbana pobre e degradada. Rio de Janeiro: Zahar, 2005.

WILSON, J. F. O. Posição de classe, redes sociais e carreiras militantes no estudo dos movimentos sociais. Revista Brasileira de Ciência Política, Brasília, n. 3, jan./jun. 2010. Disponível em http://rbcp.unb.br/artigos/rbcp-n3-36.pdf. Acesso em: 05.04. 2014. 


\section{YOUTH AND ASSOCIATIVE LIFE FROM THE PERIPHERIES OF SÃO PAULO}

\section{Gilberto Geribola Moreno}

The present article focuses on the processes of political experience of young militants from the outskirts of the city of São Paulo, Brazil. It attempts to understand associative life as a process of individualization of political actors. This study is grounded in the assumption that these actors have the opportunity to make use of past and present elements as they build up their own political repertoire. Although this article holds discussions with other works which approach militancy emphasizing the processes of political socialization, its analysys is centered around analytical subjectivity. The reflections presented here have been based on a multi-sited ethnographic research conducted in residens' Associations over the three years material. It has been allowed to say by its analysis that young militants select, appropriate or reject some political elements of the past from their own social experiences in the political field. Thus, without rebutting or submit entirely to the legacies of past, young militants recreate their own politics and relationships in this new social settings.

KEY wORDs: Youth. Politics. Generational relations. Subjectivity.

\section{JEUNESSE ET VIE ASSOCIATIVE DANS LES BANLIEUES DE SÃO PAULO}

\author{
Gilberto Geribola Moreno
}

Cet article présente une réflexion sur l'expérience politique de jeunes militants de la banlieue de São Paulo. Cette démarche s'inscrit dans l'effort de comprendre la vie associative faisant partie d'un processus de singularisation des acteurs politiques. Cela part du principe que ces acteurs ont la possibilité d'organiser des éléments du passé et du présent afin de créer un répertoire politique. L'article est en dialogue avec les travaux qui étudient le militantisme en mettant l'accent sur les processus de socialisation politique, bien qu'il opère à partir de l'instrument analytique de la subjectivation politique. La réflexion présentée ici s'appuie sur le matériel d'une recherche ethnographique multisituée réalisée pendant trois ans au sein d'associations de quartier de la banlieue de São Paulo. L'analyse de cette étude permet d'affirmer que les jeunes militants sélectionnent, s'approprient ou rejettent certains éléments politiques du passé diffusés sur le territoire, à partir de leur propre expérience sociale dans l'univers politique. Sans réfuter ni se soumettre entièrement aux legs du passé, les jeunes militants recréent différentes relations politiques et de nouvelles configurations sociales.

Mots-CLÉs: Jeunesse. Politique. Relations générationnelles. Subjectivation. \begin{tabular}{l}
\hline Gilberto Geribola Moreno - Doutor em Sociologia da Educação. Professor no Curso de Antropologia da \\
Universidade Federal da Integração Latino Americana UNILA e, também, professor substituto no Centro \\
de Ciências Sociais Aplicadas na Universidade Estadual do Oeste do Paraná - UNIOESTE. Coordenador \\
do Projeto Intervenção Poética - Círculo de Leitura de Poesias na Universidade Estadual do Oeste do \\
Paraná. Integra o Núcleo de Antropologia Urbana da USP - LabNAU, desenvolvendo pesquisas na área de \\
cidades. Suas mais recentes publicações são: Entre fronteiras: juventude, crime e relações de amizade na \\
periferia de São Paulo. Revista Ambivalências, v. 4, p. 277-310, 2017; Militantes, irmãos e cabos eleitorais: \\
vida associativa e território nas periferias da cidade de São Paulo. Mana (Rio de Janeiro. Online), v. 22, \\
p. $403-434,2016$.
\end{tabular} 
